\title{
Successful surgical management of acute type A aortic dissection associated with Crohn disease
}

\author{
John G. T. Augoustides, MD, FASE, ${ }^{a}$ Alberto Pochettino, MD, ${ }^{\mathrm{b}}$ and Reed E. Pyeritz, MD, PhD, ${ }^{\mathrm{c}}$ Philadelphia, $\mathrm{Pa}$
}

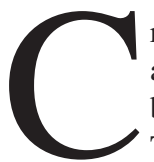

rohn disease can involve the aorta. The associated aortitis can cause aortic regurgitation, aortic aneurysm, branch vessel occlusion, and aortic mural thrombus. ${ }^{1-4}$

The aortic inflammation not only weakens the arterial wall, but it might also predispose to aortic dissection. We present a case of acute type A aortic dissection in a young woman with established Crohn disease. To the best of our knowledge, this is the first report of this thoracic aortic presentation as a manifestation of extraintestinal Crohn disease.

\section{Clinical Summary}

A 35-year-old woman with longstanding Crohn disease presented to the emergency department with acute chest pain radiating to her jaw. On physical examination, she had no pulse deficits, no arterial bruits, and an audible diastolic murmur. Her electrocardiogram and myocardial enzyme profile were normal. A computed tomographic axial scan of the chest revealed dissection of the ascending aorta and aortic arch.

She was transferred on an emergency basis to the operating room, where she underwent transesophageal echocardiography after achievement of general endotracheal anesthesia. The notable echocardiographic findings included a dilated and dissected aortic root, moderate aortic insufficiency, and dissection of the ascending aorta and aortic arch (Figures 1 and 2).

At surgical intervention on full cardiopulmonary bypass, the dilated aortic root was noted to be dissected into both the noncoronary and the right coronary sinuses. The aortic valve was trileaflet with fibrotic dysmorphic leaflets. A full root replacement was performed with a mechanical composite valved conduit. The dissected aortic arch was repaired with an extended hemiarch technique during deep hypothermic circulatory arrest and retrograde cerebral perfusion (34 minutes). The cardiopulmonary bypass time was 190 minutes, with a myocardial ischemic time of 150 minutes.

\footnotetext{
From the Cardiothoracic Section, Anesthesiology and Critical Care, Cardiothoracic Surgery, ${ }^{\mathrm{b}}$ and the Division of Medical Genetics, Department of Medicine, ${ }^{c}$ University of Pennsylvania School of Medicine, Philadelphia, Pa.

Received for publication May 2, 2007; accepted for publication May 23, 2007.

Address for reprints: John G. T. Augoustides, MD, FASE, Cardiothoracic Section, Anesthesiology and Critical Care, Dulles 680, HUP, 3400 Spruce St, Philadelphia, PA 19104-4283 (E-mail: yiandoc@hotmail.com).

J Thorac Cardiovasc Surg 2007;134:1048-9

$0022-5223 / \$ 32.00$

Copyright $\odot 2007$ by The American Association for Thoracic Surgery doi:10.1016/j.jtcvs.2007.05.048
}

The remaining perioperative course was uneventful. The patient stay in the intensive care unit was less than 24 hours. The aortic pathology was consistent with nonspecific chronic inflammation. The result of a screening test for possible syphilis was negative. The patient was commenced on prednisone after consultation with a rheumatologist. The patient was subsequently discharged home on warfarin (Coumadin) for long-term anticoagulation because of her mechanical aortic valve.

\section{Discussion}

This patient had shown extensive vascular inflammatory changes in association with her Crohn disease: chronic aortic valvulitis with scarring and consequent central aortic regurgitation, aortic root aneurysm, and dissection of the entire ascending aorta and aortic arch. She had no clinical aortic involvement distal to the left subclavian artery.

It is important to note that Takayasu's arteritis in association with Crohn disease might present with acute thoracic aortic dissection. $^{4,5}$ Our patient had no features suggestive of Takayasu's arteritis, such as pulse deficits, arterial bruits, or typical histology (granulomatous necrotizing aortitis).

In summary, the clinical observation from this case is that the aortitis of Crohn disease might lead to thoracic aortic dissection in the absence of concomitant Takayasu's arteritis. These vasculitic syndromes most likely represent a continuum that can be further characterized in the future as advances in genetic and biochemical techniques are realized.

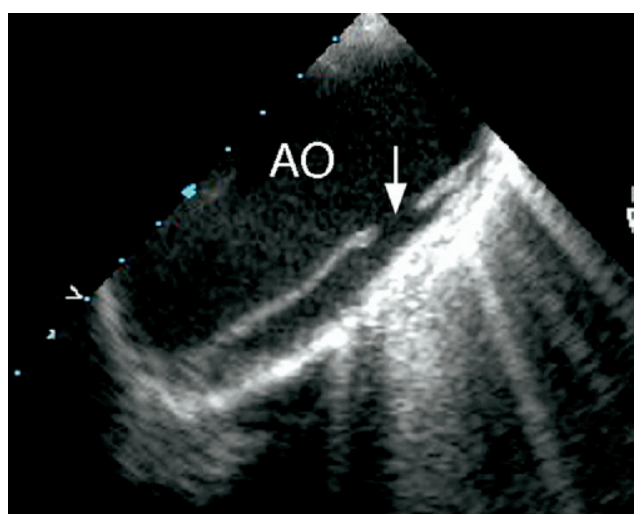

Figure 1. Transesophageal echocardiographic view of the dissected aortic arch. The arrow depicts a fenestration in the intimal flap, which, during color Doppler imaging, showed blood flow between the true and false lumens of the dissected aorta. AO, Aorta. 


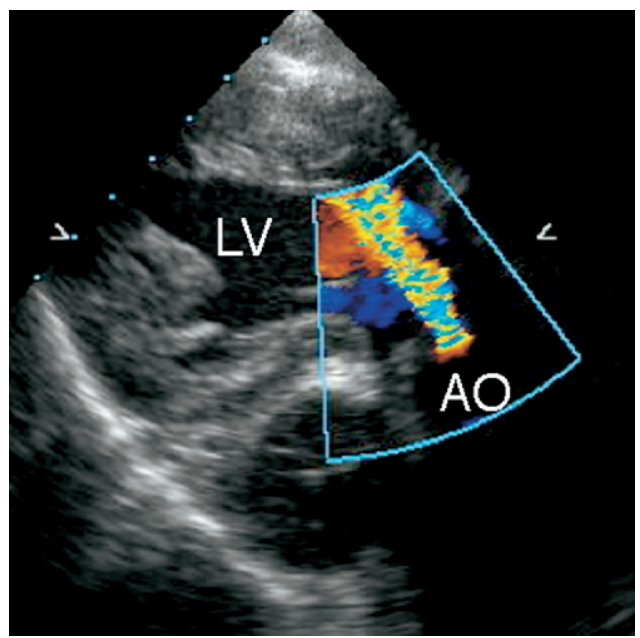

Figure 2. Transgastric echocardiographic long-axis view of the aortic valve. Color flow Doppler imaging reveals moderate aortic regurgitation. Detailed imaging of the aortic valve revealed fibrosed leaflets, leading to lack of central coaptation as the mechanism of the regurgitation. $L V$, Left ventricle; $A O$, aorta.

\section{References}

1. Novacek G, Haumer M, Schima W, Muller C, Miehsler W, Polterauer $\mathrm{P}$, et al. Aortic mural thrombi in patients with inflammatory bowel disease; report of two cases and review of the literature. Inflamm Bowel Dis. 2004;10:430-5.

2. Ozsoyler I, Yilik L, Bozok S, Ozbek C, Gurbuz A. Cardiovascular involvement in Crohn's disease in the absence of ankylosing spondylitis. Heart Vessels. 2005;20:164-6.

3. Pepper C, Munsch C, Sivananthan UM, Pye M. Unruptured aneurysm of the left sinus of Valsalva extending into the left ventricular outflow tract: presentation and imaging. Heart. 1998;80:190-3.

4. Biagi P, Castro R, Campanella G, Parisi G, Gobbini AR, Vedovini G. Takayasu's arteritis and Crohn's disease: an unusual association. Report on two cases. Dig Liver Dis. 2001;33:487-91.

5. Kanemitsu S, Shimono T, Kusagawa H, Onoda K, Yada I. Successful surgical treatment of Takayasu's arteritis associated with pyoderma gangrensoum. Ann Thorac Surg. 2005;80:1914-6.

\section{The longest functioning heart valve prosthesis?}

\section{Stephen Westaby, MD, PhD, ${ }^{a}$ Lognathen Balacumaraswami, FRCSEd FRCS(CTh), ${ }^{a}$ Nikant Sabharwal, MD, ${ }^{\text {b }}$ and} Harald Becher, MD, ${ }^{b}$ Oxford, United Kingdom

\section{Clinical Summary}

$\mathrm{I}$ n 1965, the Starr-Edwards silastic ball valve was the only commercially available heart valve prosthesis in Europe. ${ }^{1}$ We present the case of a 32-year-old man who was referred to the Hammersmith hospital that year with a severely regurgitant bicuspid aortic valve and heart failure. Before his operation, the heart-lung machine pioneer Dennis Melrose expressed concern that the Hammersmith system had not previously supported such a large patient $(190 \mathrm{~cm}, 98.5 \mathrm{~kg})$. During the opera-

From the Departments of Cardiac Surgery ${ }^{\mathrm{a}}$ and Cardiology, ${ }^{\mathrm{b}}$ John Radcliffe Hospital, Oxford, United Kingdom.

Received for publication May 4, 2007; accepted for publication May 30, 2007.

Address for reprints: Stephen Westaby, PhD, MS, FRCS, FETCS, FESC, FACC, FICA, Department of Cardiac Surgery, John Radcliffe Hospital, Headington, Oxford OX3 9DU, United Kingdom (E-mail: swestaby@ ahf.org.uk).

J Thorac Cardiovasc Surg 2007;134:1049-50

$0022-5223 / \$ 32.00$

Copyright $\odot 2007$ by The American Association for Thoracic Surgery doi:10.1016/j.jtcvs.2007.05.051 tion, the patient vividly recalls his surgeon, Professor Hugh Bentall, saying "Give it to him again," followed by 3 further shocks from the defibrillator! Eventually, the heart-lung machine and valve prosthesis proved more successful than the anesthetic, and the patient survived.

Consistent with the natural history of bicuspid aortic valves, the patient presented again in 2006 with central chest pain and an enormous ascending aortic aneurysm. ${ }^{2} \mathrm{~A}$ computed tomographic scan suggested a chronic DeBakey type II dissection (Figure 1). Transesophageal echocardiographic scanning showed a functioning ball valve prosthesis with a peak gradient of $24 \mathrm{~mm} \mathrm{Hg}$ and well-preserved left ventricular function. Both investigations indicated that the aneurysm was adherent to the posterior sternal table.

During femorofemoral cardiopulmonary bypass with profound hypothermia $\left(18^{\circ} \mathrm{C}\right)$, the sternal saw opened the aneurysm widely. Circulatory arrest was used to replace the ascending aorta and remodel the aortic root around the prosthesis and coronary ostia. The slightly discolored silicone ball remained spherical without a propensity to dislocate from the stainless-steel cage. It was retained to simplify the procedure and reduce operative time.

In 2007, the patient, the prosthesis, and the original surgeon (now aged 86 years) are in good condition. Repeat echocardiographic scanning shows a morphologically normal aortic root and ascending aorta. 